\title{
Phenylpropanoids as the biologically active compounds of the medicinal plants and phytopharmaceuticals
}

\author{
Vladimir A. Kurkin \\ Department of Pharmacognosy, Samara State Medical University, Samara, Russia \\ Email: Kurkinvladimir@yandex.ru
}

Received 1 January 2013; revised 1 February 2013; accepted 7 February 2013

\begin{abstract}
In the present paper are discussed the results of the investigations of the phenylpropanoids of the medicinal plants which are of the great interest as the sources of the neurotropic, adaptogenic, immunostimulating, antioxidative, and hepatoprotective preparations. There were shown the necessity of using of the standard samples of triandrin (Rhodiola rosea $\mathrm{L}$. tissue cultures, Salix viminalis L. barks), rosavin (Rhodiola rosea L. rhizomes), syringin, or eleutheroside B [Eleutherococcus senticosus (Rupr. et Maxim.) Maxim. rhizomes, Syringa vulgaris L. barks], and silybin [Silybum marianum (L.) Gaertn. fruits] for purpose of the standardization of the corresponding drugs and pharmaceuticals. It was shown also the significance of $\gamma$-schizandrin, chicoric acid, rosmarinic acid and lavandoside for purposes of the standardization of raw material and preparations of Schizandra chinensis Baill. fruits and seeds, Echinacea purpurea (L.) Moench. herbs, Melissa officinalis $\mathrm{L}$. herbs and $\mathbf{L a}$ vandula spica $\mathrm{L}$. flowers respectively.
\end{abstract}

Keywords: Phenylpropanoids; Medicinal Plants; Phytopharmaceuticals; Standardization; Neurotropic; Adaptogenic; Hepatoprotective; Antioxidative; Immunomodulating Activities

\section{INTRODUCTION}

The phenylpropanoids are biologically active compounds of medicinal plants which are perspective sources of the neurotropic, adaptogenic, immunostimulating, and heaptoprotective preparations [1-8]. The greatest interest are glycosides of cinnamic alcohol, $p$-coumaric alcohol, sinapic alcohol of Salix viminalis L. barks (1), Rhodiola rosea L. tissue cultures (1), Rhodiola rosea L. rhizomes (2), Eleutherococcus senticosus (Rupr. et Maxim.) Maxim. rhizomes (3), Syringa vulgaris L. barks (3), and also flavolignan silybin (4) on the base of coniferyl alcohol and flavonoid taxifolin of Silybum marianum (L.)
Gaertn. fruits. In addition, from the point of view of standardization deserve the attention of the caffeic acid and ferulic acid and their derivatives, namely chicoric acid (7), rosmarinic acid (8), and lavandoside (6), a new plant compounds, which have the chemical structure of $4-0-\beta$-D-glucopyranoside of ferulic acid. Previously, we have been isolated a series of phenylpropanoids, including new biologically active compounds [5,9], but in comparative aspects they have not been studied from the point of view the physical-chemical, spectral and pharmacological properties especially in terms of approaches to standardization and development of new drugs. Moreover, still in the references, in particular in the field of pharmacognosy, in the not yet fully formed an opinion in relation to phenylpropanoids as a special group of biologically active compounds.

The purpose of our work is the comparative study of the physical-chemical, spectral and pharmacological properties of phenylpropanoids as biologically active diagnostic significant compounds of the pharmacopeia medicinal plants and phytopharmaceuticals, which are using in Russian Federation.

\section{PLANT MATERIAL AND METHODS}

\subsection{Plant Material}

For our experiments we collected the plant materials of Rhodiola rosea (rhizomes), Syringa vulgaris (barks), Silybum marianum (fruits), Echinacea purpurea (L.) Moench. (herbs), Melissa officinalis L. (herbs) and Lavandula spica L. (flowers) cultivated in Samara region. The some drugs were collected from widely distributed plants in Samara region (Salix viminalis barks) or in Khabarovsk Krai (Eleutherococcus senticosus rhizomes, Schizandra chinensis Baill. fruits and seeds). There was studied also the biomass of Rhodiola rosea L. tissue cultures.

\subsection{Methods}

The isolation of phenylpropanoids (1-8) (Figure 1) from 
<smiles>OCC1OC(OC/C=C/c2ccc(O)cc2)C(O)C(O)C1O</smiles><smiles>COc1cc(/C=C/CO)cc(OC)c1OC1CCCCC1</smiles>

Syringin (Eleutheroside B) (3)<smiles>COc1cc2c(c(OC)c1OC)-c1c(cc3c(c1OC)OCO3)CC(C)C(C)C2</smiles>

$\gamma$-Schizandrin (5)<smiles>O=C(/C=C/c1ccc(O)c(O)c1)OC(C(=O)O)C(C(=O)O)C(=O)O</smiles>

Chicoric acid (7)

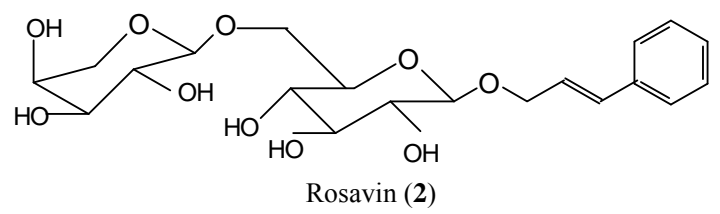<smiles>COc1cc(C2Oc3cc([C@H]4Oc5cc(O)cc(O)c5C(=O)C4O)ccc3OC2CO)ccc1O</smiles>

Silybin (4)<smiles>COc1cc(/C=C/C(=O)O)ccc1OC1OC(O)C(O)C(O)C(CO)C1O</smiles>

Lavandoside (6)<smiles>O=C(/C=C/c1ccc(O)c(O)c1)OC(Cc1ccc(O)c(O)c1)C(=O)O</smiles>

Rosmarinic acid (8)

Figure 1. The chemical structures of phenylpropanoids of investigated plants.

the plant material there was carried out by means of extraction with $70 \%$ ethanol. The separation of isolated compounds there was development with the using of column chromatography on the silica gel L 40/100 and (or) polyamide ("Woelm"). As the eluents we have been used the several solvents (chloroform, 96\% ethanol, water etc.) and their mixtures.

The structural elucidation of the isolated phenylpropanoids (1-8) was carried out by means of the UV-, ${ }^{1}$ H-NMR-spectroscopy, mass spectrometry and several chemical transformations (acetylation, methylation, acid hydrolysis and enzymatic hydrolysis). Methods of identification of the herbal material and preparations of mentioned plants were developed with the use of UV-spectroscopy TLC and HPLC.

Proton NMR experiments were performed using spectrometer "Bruker AM 300" (300 MHz). UV spectra there were registered on spectrophotometer "Specord 40" (Analytik Jena). Mass spectra of compounds there were determined by means of the spectrometer "Kratos MS-3".
TLC-analysis was carried out by means of the plates "Sorbfil" (solvent system: chloroform:ethanol, 9:1; chloroform:methanol:water, 26:14:3; $n$-butanol:glacial acetic acid:water, 4:1:2). HPLC-analysis was carried out by means of chromatograph "Milichrom-6" (Russia) with the using of the stationary reversed phase "Diasorb C-16", gradient or isocratic conditions (mobile phase: the mixtures of acetonitrile and water with the addition of $1 \%$ of glacial acetic acid).

\section{RESULTS AND DISCUSSION}

In the course of our investigations there were studied the phenylpropanoids of the medicinal plants which are of the great interest as the sources of the tonic, adaptogenic, sedative, anxiolitic, immunostimulating, antioxidative and hepatoprotective preparations. There were motivated the using of the standard samples of triandrin (1) (Rhodiola rosea L. tissue cultures, $S$. viminalis barks), rosavin (2) (Rhodiola rosea L. rhizomes), syringin (3) [Eleu- 
therococcus senticosus (Rupr. et Maxim.) Maxim. rhizomes, Syringa vulgaris L. barks], and silybin (4) [Silybum marianum (L.) Gaertn. fruits] for purpose of the standardization of the corresponding drugs and phytopharmaceuticals.

There were established the relationships between the structures of phenylpropanoids (1-4), cinnamic alcohol, $p$-coumaric alcohol, coniferyl alcohol, sinapic alcohol and their the chemical, spectral properties and biologically activities. It was shown that triandrin $(9-0-\beta$-Dglucopyranoside of $p$-coumaric alcohol) (1), rosavin (vicianoside of cinnamic alcohol (2), syringin (4-0- $\beta$-Dglucopyranoside of sinapic alcohol (3) and silybin (4) are diagnostic and dominant biologically active compounds of corresponding drugs and preparations. The standard samples of triandrin (1) (Rhodiola rosea tissue cultures, Salix viminalis barks), rosavin (2) (Rhodiola rosea rhizomes), syringin (3) (Eleutherococcus senticosus rhizomes, Syringa vulgaris barks), and silybin (4) (Silybum marianum fruits) are proposed to be used for standardization (TLC-, HPLC-analysis and UV-spectroscopy) of the mentioned medicinal plants and of their preparations. New approaches to the standardization of the medicinal plants, which contain phenylpropanoids, there were proposed and were also developed the procedures of qualitative and quantitative analysis with the using of state standard samples of silybin, rosavin, syringin (eleutheroside B).

On the basis of the study of the physical-chemical, spectral and pharmacological properties of a whole series of plant substances was substantiated the need for introduction into pharmacognosy of phenylpropanoids as the independent class of biologically active compounds [8, 9], that was reflected in the textbook "Pharmacognosy" [10]. To phenylpropanoids there were related us such medicinal plants, as Rhodiola rosea L., Echinacea purpurea (L.) Moench., Eleutherococcus senticosus (Rupr. et Maxim.) Maxim., Syringa vulgaris L., Silybum marianum (L.) Gaertn., Schizandra chinensis Baill. etc. New approaches to the standardization of the medicinal plants, which contain phenylpropanoids, there were proposed and were also developed the procedures of qualitative and quantitative analysis with the using of state standard samples of silybin, rosavin, syringin (eleutheroside B). It was shown also the significance of $\gamma$-schizandrin (5), lavandoside (6), chicoric acid (7) and rosmarinic acid (8) for purposes of the standardization of raw material and preparations of Schizandra chinensis Baill., Lavandula spica L., Echinacea purpurea (L.) Moench. and Melissa officinalis L. respectively. On the basis of the study of the physical-chemical, chemical, spectral and pharmacological properties of phenylpropanoids there was substantiated the expediency of the creation and the using of the whole series of the phytopharmaceuticals, which have the tonic and adaptogenic activities (Rhodiola rosea tinctures, Eleutherococcus senticosus extracts, Syringa vulgaris tinctures, Salix viminalis extracts, Schizandra chinensis syrups), sedative effect (Melissa officinalis L. tinctures and Lavandula spica extracts), anxiolitic activity (Melissa officinalis tinctures), immunostimulating properties (Echinacea purpurea tinctures and syrups), antioxidative and hepatoprotective activities (Silybum marianum extracts and syrups).

\section{REFERENCES}

[1] Bauer, R. and Wagner, H. (1990) Echinacea: Handbuch für artze, apotheker und andere naturwissenschaftlicher. Wissenschaftliche Verlaggeselschaft, Stuttgart.

[2] Cheminat, A., Zawatzky, R., Becker, H., et al. (1988) Caffeoyl conjugates from Echinacea species: Structures and biological activity. Phytochemistry, 27, 2788-2794. doi:10.1016/0031-9422(88)80664-2

[3] Cometa, L., Tomassini, I., Nicoletti, M., et al. (1993) Phenylpropanoid glycosides. Distribution and pharmacological activity. Fitoterapia, 64, 195-217.

[4] Koch-Heitzmann, I. and Schultze, W. (1991) 2000 Jahre Melissa officinalis L. Z. Phytotherapie, 11, 50-58.

[5] Kurkin, V.A., Zapesochnaya, G.G., Dubichev, A.G., et al. (1991) Phenylpropanoids of tissue cultures of Rhodiola rosea. Khimiya Prirodnykh Soedineniy, 27, 481-490.

[6] Kurkin, V.A. (2003) Silybum marianum (L.) Gaertn. is the perspective source of pharmaceuticals. KhimikoPharmatsevticheskiy Zhurnal, 37, 27-41.

[7] Wagner, H. (1993) Pharmazeutische biologie. Drogen und ihre Inhaltsstoffe. Gustav Fischer Verlag, New York.

[8] Kurkin, V.A. (2002) Modern aspects of chemical classification of biologically active compounds of medicinal plants. Pharmacy, 50, 8-16.

[9] Kurkin, V.A. (2003) Phenylpropanoids from medicinal plants: Distribution, classification, structural analysis, and biological activity. Chemistry of Natural Compounds, 39, 123-153. doi:10.1023/A:1024876810579

[10] Kurkin, V.A. (2007) Pharmacognosy: Textbook for the students of pharmaceutical universities. Samara State Medical University and Ofort, Samara. 